\title{
Microstructure and Properties of Low Cost TC4 Titanium Alloy Plate
}

\author{
Qiuyuan FENG ${ }^{1,2 \text {, a }}$, Lei ZHANG ${ }^{2}$, Hong PANG ${ }^{2}$, PingHui ZHANG ${ }^{1,2}$,Xuewen TONG ${ }^{1,2}$, \\ Dingchun WANG ${ }^{1,2}$ and Qi GAO ${ }^{1,2}$ \\ ${ }^{1}$ Baoti Group Ltd., Baoji 721014, China \\ ${ }^{2}$ Baoji Titanium Industry Co., Ltd., Baoji 721014, China \\ a fengqiuyuan2003@163.com ${ }^{1}$
}

\begin{abstract}
The changing law of microstructure and mechanical properties of low cost TC4 titanium alloy during deformation and annealing was investigated. The results show that the coarse cast dendritic structure of slab is broken to form rod-like or equiaxial $\alpha+\beta$ transformed microstructure by rolling deformation. After annealing, the microstructure of plate becomes uniform, moreover, the flake secondary $\alpha$ separates out and the amount of primary $\alpha$ phase decreases with the increase of annealing temperature and gradually tends to equiaxization. The tensile strength and ductility of plate show an increased tendency with deforming. When annealing temperature increases, the tensile strength firstly increases, and then reaches the maximum value at $820{ }^{\circ} \mathrm{C}$, after that, it gradually decreases. The yield strength and reduction of area show decreasing trend as a whole, but the elongation has a little change. The plate has preferable matching of strength and ductile after annealing treatment at $750 \sim 820{ }^{\circ} \mathrm{C}$ for $1 \mathrm{~h}$ in air.
\end{abstract}

\section{Introduction}

Titanium and its alloy are important metal structural materials, which possess excellent comprehensive properties, such as low density $\left(4.5 \mathrm{~g} / \mathrm{cm}^{3}\right)$, high specific strength, excellent corrosion resistance and nonmagnetic, and so on. Therefore, they have been increasingly widely used in aviation, aerospace, chemical, shipbuilding, automobile, weapons, sports, medical treatment and other industrial departments. The first practical titanium alloy "Ti-6Al-4V alloy" was successfully developed in 1954 in the United States. The properties of Ti-6Al-4V alloy in heat resistance, strength, plasticity, toughness, formability, weld-ability, corrosion resistance and biocompatibility are up to a better level. Ti-6Al-4V titanium alloy's consumption accounted for the $75 \sim 85 \%$ of all kinds of titanium alloys. Many countries in the world recognize the importance of titanium, so titanium alloy materials are being on the research and developing, and supported by practical application.

\footnotetext{
* Corresponding author: fengqiuyuan2003@163.com
} 
However, expensive cost severely limits the application of titanium alloy. Currently, research and development on low cost titanium alloy and the low-cost manufacturing technology of titanium alloy are still the important research hotspot and the development direction of Ti alloys [1-4]. Reducing raw materials price and shortening the processing procedure are the effective approach to reduce the cost of titanium alloy. During the production of titanium alloy, a lot of recycling titanium scrap is produced and its cost is only one third of titanium sponge. Using electron beam cold hearth melting (EBCHM) to replace the conventional vacuum arc refined (VAR), the scrap could be added more than $50 \%$ to dramatically reduce the raw material cost. Moreover, EBCHM can produce the slab ingots, which can be used directly to process into plate. Because of saving the cogging and forging process of circle ingots, the production flow could be shorten at maximum limit to decrease consume and save the cost [5]. Ti-6Al-4V alloy plate direct rolled from single melt by EBCHM will be applied in aviation and weapon fields [6]. EBCHM single melt technology has been investigated in America, Canada and Ukraine [7-11]. Timet Company has successfully melted Ti-6Al-4V EBCHM-only material and produced $25 \mathrm{~mm}, 50 \mathrm{~mm}$ and $64 \mathrm{~mm}$ plate with acceptable chemistry, structure and mechanical properties for armor plate applications [12]. Using Ti-6Al-4V large slab ingots produced by EBCHM, the $76.2 \mathrm{~mm}$, $50.8 \mathrm{~mm}, 25.4 \mathrm{~mm}$ and $12.7 \mathrm{~mm}$ thickness plate was rolled [13]. After testing, the mechanical property of plate shows better than the lowest demand of aviation standard and can be applied to armor and consumer applications. As for the Ti-6Al-4V titanium alloy plate, strip and plate produced by EBCHM single melt, an aerospace material specification AMS6945 had been issued in 2005 and revised in 2014 in America. In China, our company utilizes the $2400 \mathrm{kw}$ EBCHM, which imported from ALD Company in Germany, to single melt the TC4 titanium alloy slab ingot. After that, the slab ingot has to be rolled the $8 \mathrm{~mm}$ thickness plate $[14,15]$. The mechanical properties at room temperature and ballistic properties of plate meet the Chinese standard and operating requirements. These plates come into use.

In this work, the research on the microstructure and properties of TC4 titanium alloy plate rolled by EBCHM single melt slab ingot during the deforming and annealing was carried out to reveal the evolution rule of microstructure and the change law of mechanical properties of plate. The annealing regime with optimum matching between strength and ductility was obtained. The aim of this work is to provide the reference for the industrialization quantity production of the TC4 titanium alloy plates.

\section{Materials and Experimental Procedure}

TC4 titanium alloy was EBCHM melted from a combination of Ti sponge and recycling titanium scrap. The materials were precisely weighed and blended and pressed into small compacts for melting. The raw materials were electron beam melted and cast into $270 \mathrm{~mm}$ $\times 1085 \mathrm{~mm} \times$ approximately $5000 \mathrm{~mm}$ ingot molds weighing approximately $6000 \mathrm{~kg}$. The chemistry of the slab is well within specification requirement of GB/T 3620.1-2007 Chinese standard. The $\beta$ transform temperature is $974{ }^{\circ} \mathrm{C}$ measured using metallographic method. The ingot was machined from the ingot sidewalls to prepare the slab for rolling. The slab ingot was rolled by using cross rolling process on $1200 \mathrm{~mm}$ four-high reversing hot mill under $20 \sim 50{ }^{\circ} \mathrm{C}$ of $\beta$ transform point to produce the $8 \mathrm{~mm}$ thickness plate. The plate was annealed in accordance with the annealing regime of $720 \sim 950{ }^{\circ} \mathrm{C}$ for $1 \mathrm{~h}$ and cooled in air.

The microstructure and properties of TC4 titanium alloy plate from ingot to plate during deforming and annealing were analyzed and tested, and then the heat treatment regime with best matching between microstructure and mechanical properties was optimization selected. Room temperature tensile test was carried out on a CMT 5105 electron all-purpose tester according to Chinese standard GB/T 228.1-2010 "Metallic materials-Tensile testing-Part 1: 
Method of test at room temperature", and microscopic examination was observed and analyzed by using an Axiovert 200MAT metallographic microscope.

\section{Results and Discussion}

\subsection{The Microstructure and Properties of TC4 Titanium Alloy Plate During Deforming}

Fig.1 shows the microstructure of TC4 titanium alloy plates after different heating number deforming. From the Fig.1 (a), it can be observed that the original as-cast structure is coarse with the dendrite crystal structure in the intracrystalline. After first heating deforming, as-cast dendrite crystal structure was broken to form the columnar structure, see Fig.1 (b). After second heating deforming, the coarse grains were broken to form fine grains, and columnar structure gradually changed as equiaxial or strip structure. The structure was flattened or elongated along the rolling direction, see Fig.1 (c). After third heating deforming, the grains of finished plate became fine again, and the rod-like structure mostly changed to equiaxial $\alpha+\beta$ transform structure, see Fig.1 (d). The refining of grains and evolution of structure are related to the mechanical properties at room temperature.

Table 1 gives the mechanical properties at room temperature after different heating number deforming. From the Table, it can be seen that both tensile strength and plasticity of plates present the increasing trend. The strength and ductility enhance obviously after rolling compared to that of TC4 titanium alloy ingot. This can be attributed to the mechanical properties depend on the structure, when the equiaxial structure is more refine, the strength and ductility will be higher. The strength and ductility relate to the slide length of dislocation during the metal deform, the shorter the slide length of dislocation, the high the strength and ductility will be. Slide length of dislocation of equiaxial structure depends on the amounts of primary $\alpha$ phase. If the equiaxial $\alpha$ phases are more and the grains are refine, the slide length of dislocation become short, this will make the dislocation stuff become less, resulting in the strength and ductility become better. During the rolling deformation, the sufficient deformation can make the dislocation source of slip system start to come into being the corresponding slide, in favor of spheroidization of primary $\alpha$ phases. Meanwhile, the large the degree of deformation, the amounts of rod-like $\alpha$ broken by flow stress will become more, which can provide more nucleation opportunity for recrystallization. As the phase constitution and microstructure pattern, the degree of grains is an important factor for the tensile strength of alloy. Fine grains could be obtained with good strength and ductility, but coarse grains could cause the plasticity and strength decrease at room temperature. The change law of mechanical properties of plate at room temperature showed in Table 1 agrees with the evolution rule of microstructure illustrated in Fig.1.
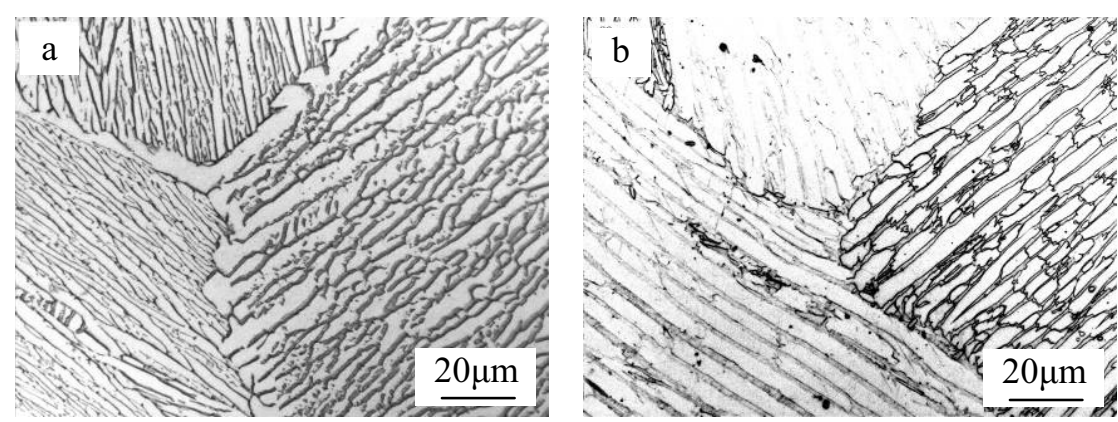

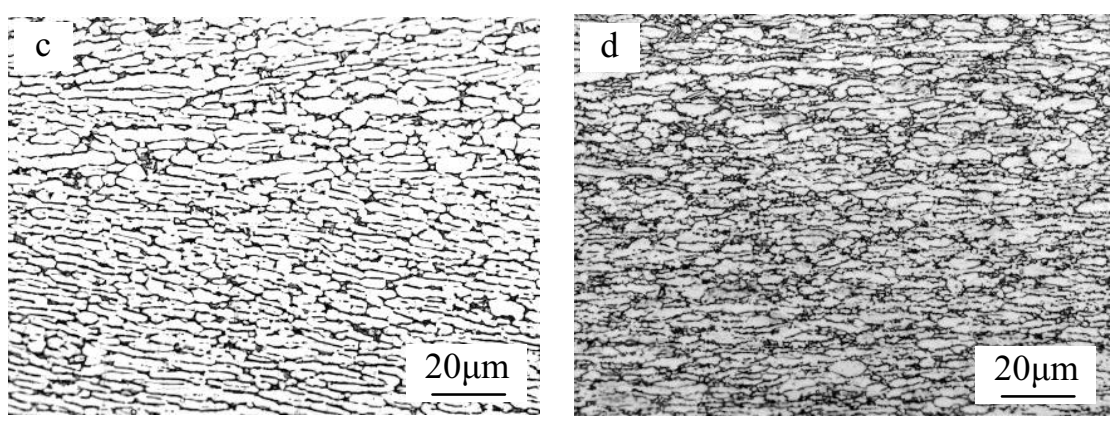

Fig.1 Microstructure of TC4 titanium alloy plates after different heating number deforming (a) Original as-cast structure; (b) Structure after first heating deforming;

(c) Structure after second heating deforming; (d) Structure of finished product

Table 1 room-temperature mechanical properties of tc 4 titanium alloy plates After different heating number deforming

\begin{tabular}{cccccc}
\hline & Status & $\mathrm{R}_{\mathrm{m}} / \mathrm{MPa}$ & $\mathrm{R}_{\mathrm{p} 0.2} / \mathrm{MPa}$ & $\mathrm{A} / \%$ & $\mathrm{Z} / \%$ \\
\hline $\begin{array}{c}\text { Ingot } \\
\begin{array}{c}\text { Plate after first heating } \\
\text { deforming }\end{array}\end{array}$ & $\mathrm{R}$ & 812 & 765 & 7 & 21 \\
$\begin{array}{c}\text { Plate after second } \\
\text { heating deforming }\end{array}$ & $\mathrm{R}$ & 961 & 894 & 13 & 27 \\
Finished product & $\mathrm{R}$ & 1013 & 952 & 12 & 30 \\
\hline
\end{tabular}

\subsection{The Microstructure and Properties of TC4 Titanium Alloy Plate after Annealing}

Fig. 2 shows the microstructure treated at $720 \sim 950^{\circ} \mathrm{C}$ for $1 \mathrm{~h}$ and cooled in air. From this Figure, it can be observed that the microstructure takes on some changes, but the structure consist of rod-like or equiaxial $\alpha+\beta$ transformed structure, the grains size and morphology are very similar (see Fig. 2a-d). With annealing temperatures increase continuously from $820^{\circ} \mathrm{C}$, the microstructure of plates change obviously compared to that of plates at low temperature. The primary $\alpha$ phase content decrease gradually and the size become large, and the grains change to equiaxial. Meanwhile, the amount of $\beta$ transformed structure increase gradually (see Fig. 2e-f) and secondary flake-like $\alpha$ phase precipitate from $\beta$ phase (see Fig. 2f).
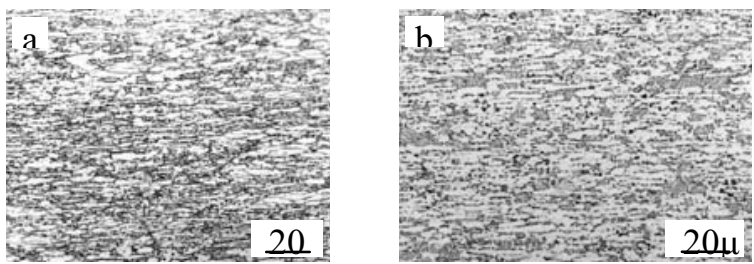

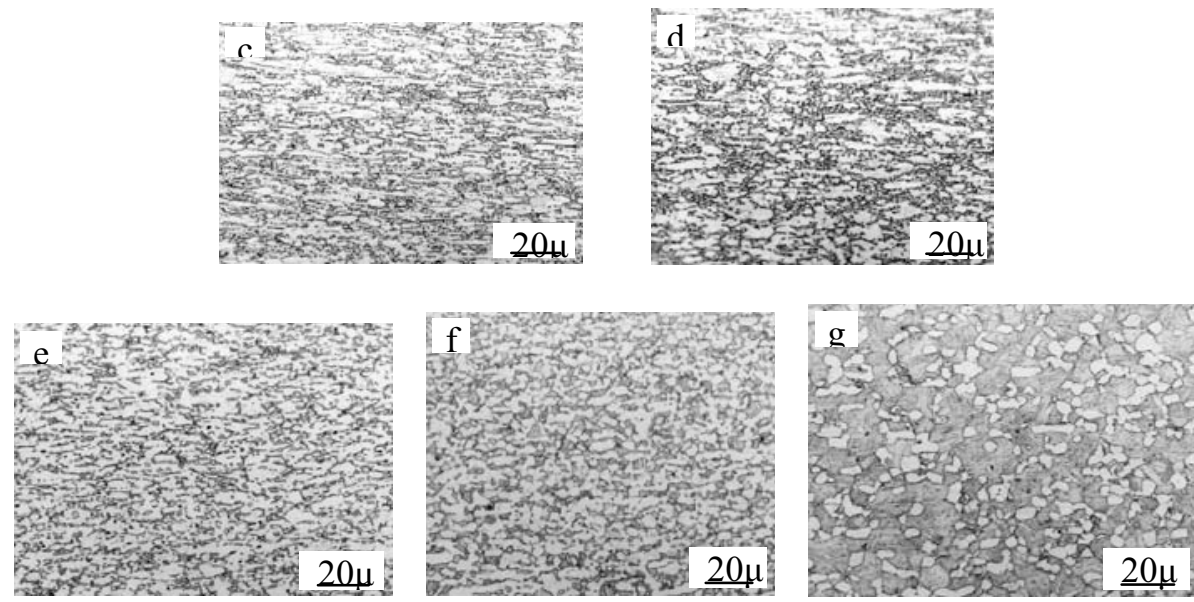

Fig.2 Microstructure of TC4 titanium alloy plates after different annealing temperatures (a) $720^{\circ} \mathrm{C}$; (b) $750^{\circ} \mathrm{C}$; (c) $780^{\circ} \mathrm{C}$; (d) $820^{\circ} \mathrm{C}$; (e) $850^{\circ} \mathrm{C}$; (f) $900^{\circ} \mathrm{C}$; (g) $950^{\circ} \mathrm{C}$

The microstructure evolution of plate gives rise to the change of mechanical properties. Fig. 3 illustrates the ambient mechanical properties of plates annealed at $720 \sim 950{ }^{\circ} \mathrm{C}$ for $1 \mathrm{~h}$ and cooled in air. It shows that the mechanical properties of plates all meet the requirement of criterion under different annealing temperature. From this figure, it can be found that the ambient tensile strength $\left(\mathrm{R}_{\mathrm{m}}\right)$ presents increment trend at first, and reaches the maximum value at $820^{\circ} \mathrm{C}$, and then it takes on gradually decreasing trend with the temperatures rising from $720{ }^{\circ} \mathrm{C}$ to $950{ }^{\circ} \mathrm{C}$. The yield strength $\left(\mathrm{R}_{\mathrm{p} 0.2}\right)$ and reduction of area $(\mathrm{Z})$ exhibit descending trend as a whole, while the elongation percentage (A) changes little. The reason can be contributed to that the tensile strength changes with the variation of equiaxial structure, the more the equiaxial structure, the higher the tensile strength [16]. When the annealing temperature gradually goes up to $820{ }^{\circ} \mathrm{C}$, the content of equiaxial $\alpha$ phases in TC4 titanium alloy are the maximum, therefore, the tensile strength reaches the peak value. With the annealing temperatures raises little by little, the content of equiaxial $\alpha$ phases reduce gradually, resulting in decreasing the tensile strength. Although secondary flake-like $\alpha$ phases precipitate from alloy with annealing temperature increasing, the tensile strength is improved. Due to the higher temperature, the amount of equiaxial $\alpha$ phases in alloy reduces significantly. Furthermore, the grains become coarse, which would result in evidently reduce the tensile strength of the alloy.

From Fig. 3, it can be seen that after annealing at $750 \sim 820^{\circ} \mathrm{C}$ for $1 \mathrm{~h}$ and cooled in air, although the yield strength and reduction of area decline slight, the change amplitude is not large. For comprehensive consideration, TC4 alloy plates can acquire the strength-ductility best matching at this temperature scope to anneal treatment. Consequently, this heat treatment regime could be suggested for industrialization batch production of the TC4 titanium alloy plates. 


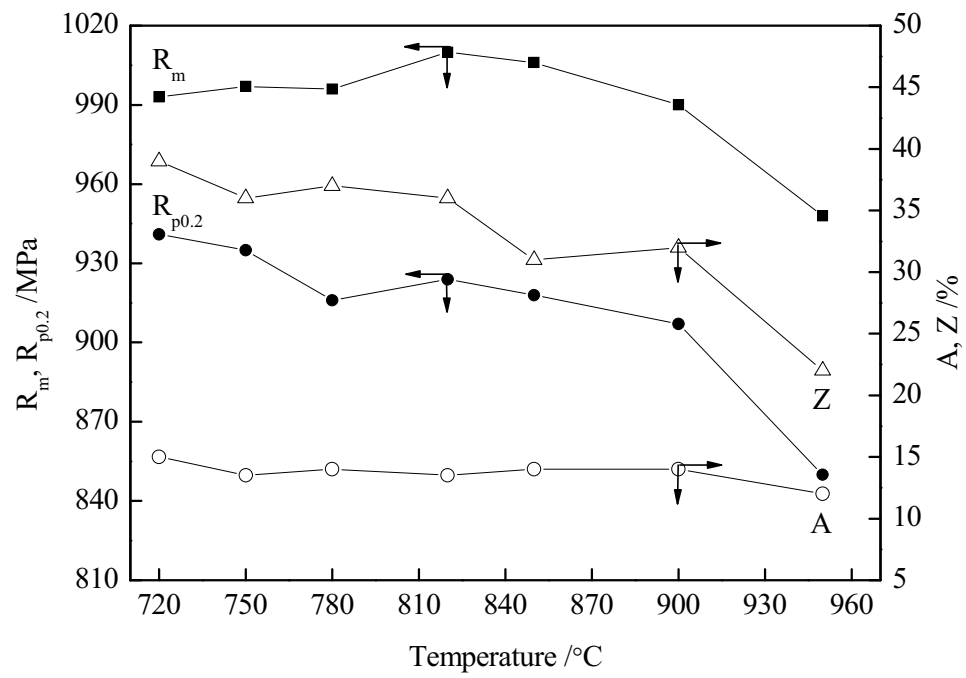

Fig.3 Room-temperature mechanical properties of TC4 titanium alloy plates after different annealing temperatures

\section{Conclusions}

(1) With increasing the deforming heating number, the coarse as-cast grains of TC4 alloy slab ingot produced by EBCHM was broken. The dendrite crystal structure changed to equiaxed $\alpha$ transformed structure, as a result, the mechanical properties of plates improved dramatically.

(2) After annealing, the structure of TC4 alloy plates becomes more uniformity and equiaxial. Secondary $\alpha$ phase precipitates with flake-like and the amount of primary $\alpha$ phase decrease with the temperature increasing. The tensile strength of plate firstly shows increase, after that, it displays decrease trend. The yield strength and reduction of area totally present the decrease trend, but the elongation percentage changes little.

(3) After annealing at $750 \sim 820{ }^{\circ} \mathrm{C}$ for $1 \mathrm{~h}$ and cooled in air, the optimum strength-ductility matching can be acquired.

\section{Acknowledgements}

This work was supported by National High Technology Research and Development Program of China (863 Program) (No. 2013AA09A108).

\section{References}

1. R.P. Guo, B.S. Sun, B.B. Gao. Low cost manufacturing technology of titanium alloy used in ordnance equipment. Ordnance Mater. Sci. Eng., 31 (2008): 83-86. (in Chinese)

2. W. Gao, C.X. Zhang. Process of the low-cost titanium alloys and its military application. Titanium Industry Progress, 25 (2008): 6-10. (in Chinese)

3. W.Y. Zhang. Research progress of high-performance and low cost titanium alloy. Aeronautical Manuf. Technol., 5 (2011): 74-76, 79. (in Chinese)

4. Z.S. Zhu, G.Q. Shang, X.N. Wang, Y. Fei, J. Li. Research and development of low cost and high performance titanium alloys. Titanium Industry Progress, 29 (2012): 1-5. (in 
Chinese)

5. F. Chen, L. Chen, B. Guo, Q. Peng, S.X. Guo, L.L. Mao. Advantages and disadvantages of electron beam cold hearth melting. Chin. J. Nonferrous Met., 20 (2010): s873-s876. (in Chinese)

6. L.L. Yu, X.N. Mao, Y.M. Zhang, Z.M. Hou, W.G. Lei, C. Wang, P. Gao. Development of electron-beam cold hearth single melt process for titanium alloy ingots. Titanium Industry Progress, 26 (2009): 14-18. (in Chinese)

7. H.R. Harker. Experience with large scale electron beam cold hearth melting (EBCHM). Vacuum, 41 (1990): 2154-2156.

8. A. Mitchill. The electron beam melting and refining of titanium alloys. Mater. Sci. Eng., A, 263 (1999): 217-223.

9. A. Mitchill. Composition control in hearth melting processes, in Lütjering G, Albrecht J (Eds.), Ti-2003 Science and Technology, Proceedings of the 10th World Conference on Titanium, Volume I, WILEY-VCH Verlag GmbH \& Co. KGaA, Weinheim, 2003, pp. 189-196.

10. A.N. Kalinyuk, N.P. Trigub, V.N. Zamkov, O.M. Ivasishin, P.E. Markovsky, R.V. Teliovich, S.L. Semiatin. Microstructure, texture, and mechanical properties of electron-beam melted Ti-6Al-4V. Mater. Sci. Eng., A, 346 (2003): 178-188.

11. H.V. Zhuk, P.A. Kobryn, S.L. Semiatin. Influence of heating and solidation conditions on the structure and surface quality of electron-beam melted Ti-6Al-4V ingots. J. Mater. Process. Technol., 190 (2007): 387-392.

12. J. S. Montgomery, G.H. Wells Martin. Titanium armor applications in combat vehicles. JOM, 53 (2001): 29-32.

13. J.R. Wood, J.C. Fanning. Direct production of Ti-6Al-4V alloy plate from electron beam cold hearth melted slab ingot, in Lütjering G, Albrecht J (Eds.), Ti-2003 Science and Technology, Proceedings of the 10th World Conference on Titanium, Volume I, WILEY-VCH Verlag GmbH \& Co. KGaA, Weinheim, 2003, pp. 181-188.

14. Q.Y. Feng, H. Pang, L. Qiao, X.W. Tong, R. Liu, W.J. Ye, D.C. Wang, Q. Gao. Preparation of low-cost TC4 titanium alloy plate. Chin. J. Nonferrous Met., 23(2013): s353-s357. (in Chinese)

15. X.W. Tong, S.X. Hui, L. Qiao, W.J. Ye, P.H. Zhang, H. Pang, R. Liu, Q.Y. Feng, Y. Yu, Y.N. Dong, J. Wang and X.Y. Song, China Patent, CN 104451213 A. (2015)

16. Z. Zhang, W. Li, Q. Liao, P. Hou, H. Wu, X.D. Zhang. Effect of forging process on microstructure and mechanical properties of TC10 titanium alloy. Mechanical Engineering \& Automation. 3 (2014): 108-109, 111. (in Chinese) 